\title{
PROJETO PEDAGÓGICO DOS PARÂMETROS CURRICULARES NACIONAIS: IDENTIDADE NACIONAL E CONSCIÊNCIA HISTÓRICA
}

ERNESTA ZAMBON I*

RESU M 0 : Este artigo tem como objetivo trabalhar a construção da identidade nacional e a consciência histórica como referenciais do projeto pedagógico contido nos parâmetros políticos e culturais apontados pela cultura política e histórica. Pesquisei nos atuais Parâmetros Curriculares N acionais o conceito de "identidade nacional" com o objetivo de analisar como foi pensado o processo de formação de uma consciência histórica.

Palavras-chave: H istória. Projeto pedagógico. Parâmetros curriculares.

\section{Political-pedagogic project of the "Brazilian Curricular Parameters": national IDENTITY and historical CONSCIOUSNesS}

ABST RACT : T his paper aims at exploring the national identity and historical consciousness building as references of the pedagogic project that underpins the cultural and political parameters emerging from the cultural and historical policies. A review of the "Brazilian Curricular Parameters" focusing on the "national identity" concept was carried out in order to analyze which conceptions oriented the elaboration process of a historical consciousness.

Key words: $\mathrm{H}$ istory. Pedagogical project. Curricular parameters.

* Professora da Faculdade de Educação da Universidade Estadual de Campinas (Un ICAM P). E-mail: ezamboni37612128@aol.com 
presente texto é o resultado parcial de uma pesquisa que ora de senvolvo sobre a construção do conhecimento escolar e tem como fundamento os parâmetros culturais apontados pela cultura política e pela história, tomando como referência os conceitos de "identidade nacional" e "consciência histórica".

0 termo "cultura política" começou a ser utilizado na América Latina no final da década de 1980, no período da transição política entre os governos militares ditatoriais e a instalação dos governos democráticos.

N essa época, a maior parte da população sul-americana estava excluída e marginalizada do consumo dos bens socialmente produzidos, dos direitos políticos e impossibilitada culturalmente de participar do mundo da produção. G rupos organizados levantaram suas vozes e exigiram o direito de serem reconhecidos socialmente, o direito a um teto, à habitação, à educação, à produção, à saúde e sobretudo que suas identidades fossem reconhecidas e respeitadas. N este contexto de transição, de mudanças políticas e sociais, aconteceu no Brasil, como em outros países da América Latina: o fim da ditadura militar, a retomada das eleições diretas para os cargos executivos e, em 1988, uma nova Constituição nacional foi promulgada, ficando conhecida como a Constituição Cidadã.

N esta nova Carta Constitucional os direitos políticos da grande maioria da população passaram a ser considerados, como os dos povos indígenas, das mulheres, dos trabalhadores e do movimento dos semterra.

As diretrizes das políticas públicas desse período, voltadas para a cultura e a educação, incorporaram metas de conservação e recuperação do patrimônio nacional (ecológico e cultural), das memórias múltiplas, reconhecendo as diferentes identidades do povo brasileiro. Portanto, mudanças políticas nacionais exigiram outras diretrizes para a educação. Respondendo às mudanças, na década de 1990, o M inistério da Educação propôs à sociedade novos Parâmetros Curriculares N acionais (PCNS) tanto para o ensino fundamental como para o ensino médio, assentados nos princípios da cidadania, da ética e da pluralidade cultural.

Preocupada em conhecer o conceito "identidade nacional" que nortearia a formação da juventude via o processo educacional, tomei como referência oS PCn s pela qualidade de um documento oficial. Pesquisei 
o tratamento dado à categoria "identidade nacional" com o objetivo de analisar o processo proposto para a formação de uma consciência histórica. N este sentido, a recuperação das memórias nacional e dos grupos sociais constitui os elementos básicos que compõem o fundamento da formação da identidade nacional, assim como da construção do conceito de "nação". N esse documento as identidades culturais que formam 0 povo brasileiro são tratadas no tema transversal "pluralidade cultural", considerada

a temática da Plural idade C ultural referente ao conhecimento eà valorização das características étnicas e culturais dos diferentes grupos sociais que convivem no território nacional, às desi gual dades socioeconômicas e à critica às relações sociais discriminatórias e excludentes que permeiam a sociedade brasilei ra (...). C onsiderar a diversidade não significa negar a existência de características comuns, nem a possibilidade de constituírmos uma nação (...). Pluralidade C ultural quer dizer a afirmação da diversidade como traço fundamental na construção de uma identidade nacional que se opõe e repõe permanentemente. (Pluralidade C ultural, 1997, p. 19)

Portanto, considerar as múltiplas características da identidade nacional é valorizar a dinâmica dos traços culturais existentes em dois planos: nos micros e macroorganismos sociais. N os microorganismos são considerados os múltiplos e heterogêneos grupos sociais que vivem e convivem nos diferentes espaços geográficos do território nacional e no macroorganismo todos os movimentos e grupos sociais existentes no país, em sua permanente renovação.

Ao abordar esta questão é importante nos reportarmos historicamente a qual era a finalidade da história como disciplina escolar. A história como disciplina escolar sempre trabalhou com as noções de "identidade nacional", "cidadania", "Estado" e "nação". H istoricamente, o ensino de história foi marcado desde 0 século XIX pelo ideário das nacionalidades; na França, o discurso liberal defendeu a laicização da sociedade e a formação da nação moderna. Estes princípios foram os norteadores do sistema educacional francês, como também da organização dos currículos de história. No Brasil, sob o manto do ideário liberal, em 1838 foi criado um programa de ensino de história para o Colégio Pedro II, do Rio de Janeiro, que reafirmava a tendência vigente. Iniciava esse programa com 0 estudo geográfico do território nacional, a organização social, política e 
Projeto pedagógico dos Parâmetros Curriculares $\mathrm{N}$ acionais...

cultural dos habitantes encontrados pelos europeus - os índios -, e em seguida estudava-se a política portuguesa de exploração e colonização, os processos religiosos de catequização, o negro como um trabalhador escravo. Este conteúdo programático, a partir dessa temática, criou os fundamentos da unidade e da hegemonia nacional. Esse programa constituiu durante muitas décadas o modelo para o ensino de história em nível primário e secundário. Fundamentados no positivismo, os programas enfatizaram a história dos fatos políticos, o Estado foi valorizado como gestor e controlador da nação e seus dirigentes eram os sujeitos que a juventude deveria ter como modelo. 0 discurso histórico, além de ser enciclopédico e elaborado com a idéia de progresso, deveria dar visibilidade à nação, que estava em processo de construção, e os seus articuladores políticos constituíram os sujeitos históricos, portanto a história como disciplina escolar era o lugar privilegiado para se trabalhar a moral e a ética como valores universais, constituindo a pedagogia da nação. Estes princípios que condicionaram a escolha de conteúdos a serem ensinados e as metodologias a serem trabalhadas. A história tornou-se o sinônimo da nação e da civilização (Zamboni, 1999, p. 7-22).

N o período republicano, esta concepção de história não só continuou como, também, foi aprofundada. Nadai, que estudou o período, afirma:

As representações, no ensino dehistória, que procuravam expressar as idéias de nação e de cidadão estavam embasadas na identidade comum de seus variados grupos étnicos e classes sociais constitutivos da nacional idade brasileira. 0 fio condutor do processo histórico centralizou-se, assim, no colonizador português e, depois, no imigrante europeu e nas contribuições parietárias de africanos eindígenas. ( $\mathrm{N}$ adai, 1993)

N as reformas curriculares de Francisco Campos, em 1931, e na de Gustavo Capanema, em1942, em plena ditadura de Getúlio Vargas, a questão nacional continuou sendo o fio condutor do ensino de história e do sistema educacional tanto na formação política dos jovens como na formação da consciência nacional. A propaganda imagética, explorando as emoções, os sentimentos, a memória afetiva, os símbolos, imagens, rituais, reforçou o princípio da nacionalidade e facilitou a centralização política, divulgando a sua ideologia: nos livros didáticos, no rádio, nas paradas militares, nas apresentações de estudantes em praça pública, principalmente por ocasião das festas cívicas, na imprensa falada, escrita 
e cinematográfica. 0 presidente Vargas criou o D epartamento de Imprensa e Propaganda (DIP) encarregado de organizar e controlar todas as manifestações publicas e divulgar as ações governamentais reforçando a idéia de uma identidade nacional comum. Procedimento semelhante ocorreu, na década de 1950, na Argentina, durante o governo de Perón. As imagens de Evita e Perón estavam nos meios de comunicação e ilustravam os livros didáticos, formando o sentimento de identidade nacional. M erece destaque que a política peronista de propaganda foi mais contundente que a do período varguista, no Brasil.

N o Brasil, na década de 1950, tivemos uma nova orientação política durante o governo de Juscelino Kubitschek e o viés nacionalista continuou sendo reforçado, com a introdução dos estudos de história da América, com o ideário de Brasil grande, moderno, industrial, homogêneo de norte a sul. Os princípios que nortearam o currículo de história da América foram nacionalismo, americanismo e civilização. D iferentemente das propostas anteriores, a história da América foi introduzida independentemente da história geral e/ou da Europa. Era a tentativa de reforçar a identidade americana e distanciar o Brasil da Europa. Como afirma D ias: "O Estado e as elites e os intelectuais brasileiros, ao se voltarem para si mesmos em torno da construção da $\mathrm{N}$ ação, utilizam também como ponto de referência os demais povos americanos, que servirão como um espelho para fazer revelar a sua própria imagem." (D ias, 1997).

Esta proposta de estudo da história colonial americana, no currículo, permaneceu até o final da década de 1950. Com a consolidação da Revolução C ubana, a nova Lei de D iretrizes e Bases da E ducação (4.024/ 61) e o início dos governos militares no continente americano, a disciplina história da América e os temas ligados à identidade latino-americana são abandonados pela própria força da lei. Foi transferida para os estados da Federação a responsabilidade na elaboração dos currículos, e a disciplina história da América deixou de fazer parte da grade curricular.

D urante a ditadura militar foi aprovada pelo Congresso $\mathrm{N}$ acional uma nova Lei de Diretrizes e Bases da Educação, conhecida como a 5.692/71, que modificou o sistema escolar, criando três áreas de conhecimento interdependentes: Comunicação e Expressão, Estudos Sociais e Artes e Comunicação, e o ensino fundamental passou de quatro para oito anos. 0 Estado atendeu as necessidades da população urbana, apa- 
Projeto pedagógico dos Parâmetros Curriculares $\mathrm{N}$ acionais...

rentemente a escola se democratizou, mas não se conseguiu equilibrar 0 binômio qualidade/quantidade, isto é, ter um ensino de qualidade com um maior número de alunos e que possuíam marcantes diferenças culturais e sociais, não se conseguiu pensar na heterogeneidade cultural e social do povo brasileiro. A escola passou a ter um novo perfil social e cultural, foi reduzida a carga horária das disciplinas história/geografia e foram inseridas no currículo as disciplinas de Educação M oral e Cívica (EMC) e O rganização Social e Política do Brasil (OSPB), portadoras de forte carga ideológica. O s objetivos centrais foram a formação da cidadania, concebida como a formação do "bom cidadão", e da identidade nacional pela via da análise do seu processo de formação política. N esse período foi intensa a propaganda imagética de caráter nacionalista, financiada por grandes empresas particulares, e que se apresentava como se fosse de caráter oficial. Era uma propaganda de natureza política que apelava para o sentimento de identidade e cultura nacionais e tinha um caráter nacionalista, desenvolvimentista e popular.

Após a abertura política, na década de 1980, com o processo de redemocratização nacional, uma nova Lei de D iretrizes e Bases da Educação foi promulgada em 1998. D ecorrente dessa lei foram organizados os Parâmetros C urriculares N acionais (PCNS), para o ensino fundamental e médio, anulando os currículos anteriormente organizados. O s temas identidade e cidadania ficaram mais evidentes nesses novos parâmetros, se comparados com os currículos anteriores, e tiveram como meta focalizar a formação da cidadania entendida

como o direito de participar de uma sociedade tendo direito deTer direito, bem como construir novos direitos, rever osjá existentes (...). Admitir e defender direitos humanos significa reconhecer não apenas esta ou aquela propriedade de al guns sujeitos, mas que o direito de ser humano éum estatuto que todas as pessoas têm o dever moral de, consciente e voluntariamente, conceder-seumas às outras. (PCN S, p. 54)

0 entendimento dado a este conceito de cidadania é dinâmico, abrangente, implicando a percepção do outro, com característica de mobilidade e mudanças. N o estudo sobre o processo de formação da identidade brasileira, deparamos com uma diversidade de expressões étnicas, culturais, sociais e antropológicas que caracterizam o povo brasileiro.

$\mathrm{N}$ as propostas curriculares o estudo da noção de identidade passa pela discussão do caráter brasileiro e é visível pelo processo de compara- 
ção, destacando as semelhanças e as diferenças existentes entre os grupos étnicos como brancos, negros, índios, mestiços e outros. A identidade nacional é construída e perceptível via as representações simbólicas como a bandeira nacional, as moedas, os selos, os hinos e os rituais presentes nas festas cívicas, populares, em jogos esportivos, nos funerais de pessoas que se destacaram no cenário nacional, como o do corredor Ayrton Senna. $\mathrm{N}$ esse momento as discussões sobre identidade nacional passam pelo diferente, e pelos antagonismos existentes entre os grupos sociais e a nação é concebida como algo em construção. N as paradas militares e/ou escolares, nas comemorações cívicas são colocadas em destaque as identidades dos diversos grupos existentes. 0 s grupos são organizados em batalhões que desfilam pelas ruas dando visibilidade às suas características, às suas tradições e cada um deles representa no corpo e nas vestes determinados momentos da história nacional. N esse momento, há um ritual em ação: os que desfilam e os que assistem estão nas calçadas parados, aplaudindo a nação e os seus símbolos que passam, sacralizando a memória nacional.

Como exemplo do que tenho afirmado, cito os acontecimentos que envolveram o povo brasileiro, em 2002, na final da Copa do M undo de Futebol; foi a vitória do pentacampeonato do Brasil. 0 grande símbolo da festa foi a bandeira nacional, que expressava a união, a identidade, o povo vitorioso. A bandeira estava nas roupas, nas janelas, nos carros e o verde, o amarelo e o azul coloriam os rostos, o corpo do povo brasileiro. O s jogadores de futebol, ao desembarcarem em Brasília, foram recebidos como heróis pelo presidente da República, foram condecorados com medalhas de honra ao mérito e desfilaram pela cidade em carro aberto. A bandeira nacional flutuava nos ares, o povo cobria-se com ela, chorava, ria e identificava-se com os jogadores, de origem pobre como ele. O s jogadores são heróis circunstanciais, passageiros que, naquele momento, representavam a identidade nacional, a nação. Em uma situação como essa se corre o perigo de homogeneizar a identidade nacional e obstruir a consciência histórica.

A formação de uma identidade nacional, na escola, começa com os livros didáticos, com a sacralização de certos acontecimentos históricos e personagens que os representam, como Tiradentes, D. Pedro I, princesa I sabel. Freqüentemente as narrativas dos textos didáticos são ilustradas com fotografias, desenhos e charges. Como afirmam Lima e Fonseca: "As pinturas representando episódios consagrados pela histo- 
Projeto pedagógico dos Parâmetros Curriculares $\mathrm{N}$ acionais...

riografia oficial acabaram por tornar-se a memória visual da nação" (Siman, 2001, p. 94). Jonathas Serrano, professor do Colégio Pedro II, destacou em 1918 a importância da observação das imagens pelos jovens, para a compreensão dos fatos históricos. As noções de identidade nacional e nação, também, foram trabalhadas e divulgadas em telas que representam fatos históricos como a Independência do Brasil, a primeira missa, a morte de Tiradentes, a Batalha de Guararapes, pintadas por artistas que receberam todo o apoio do governo imperial, como Pedro Américo, Vítor M eireles, considerados pintores oficiais da M onarquia. Portanto, a formação de uma identidade nacional e do conceito de nação é um processo ideológico que na escola passa necessariamente pela conservação de uma memória nacional e pela formação de uma consciência política. As propostas educacionais do Estado não discutem no processo educativo que a formação da identidade nacional e da nação são construções sociais em que o povo é sujeito. Para Künzle (2003, p. 30), "O poder do Estado aparece como uma propriedade de poucos; 0 Estado deve ser forte para que se faça o progresso dentro da ordem e o governante, além de pai enérgico do povo, deve ser o salvador da pátria".

É necessário que os educadores assim como os historiadores se preocupem, na escola, com a formação de uma consciência social e política dos educandos, fornecendo elementos para que pensem historicamente. Isso significa pensar a nação como um espaço social de inclusão de todas as camadas sociais e não olharem os movimentos sociais e políticos das massas como ações direcionadas à ingovernabilidade.

Em uma era de globalização, na qual estamos vivendo, onde há o esfacelamento de nossas particularidades e individualidades, o sentimento de pertencer a um lugar, a um grupo no qual desempenhamos um papel social, ao qual estamos emocionalmente e afetivamente ligados e com 0 qual nos identificamos, é muito importante para o ser humano e sua formação como sujeito histórico. N este processo de busca da identidade, de construção de uma nação participativa, a história tem um papel fundamental, pois é a base de sustentação, do conhecimento fundante do presente. Entretanto, essa identidade nos currículos aparece de forma muito simplista, fundada na caracterização dos aspectos culturais e sociais nos seus traços mais aparentes do grupo a que pertencemos. Essa identidade é mais forte na primeira fase do ensino fundamental e tende a desaparecer nos demais níveis de ensino. 
Apesar do papel que desempenha a história no processo formativo de crianças e adolescentes, inúmeras críticas adjetivam a importância da história no currículo, afirmando que ela não tem base científica, é uma disciplina que se fundamenta na memorização de fatos escolhidos arbitrariamente, escolhidos por grupos que não pertencem à categoria dos excluídos, e não serve para nada. Entretanto, afirmo que há um distanciamento entre o senso comum e as metas governamentais; as diretrizes governamentais podem ter encaminhado a educação em um determinado sentido, em uma determinada direção e a ausência de educação política leva-nos a fazer afirmações de que a história no ensino não tem importância, o não saber ver, observar e analisar pode ser muito significativo. Este fenômeno não é, infelizmente, uma prioridade brasileira, e os processos de dominação são vários, incluindo o descarte que se fez do conhecimento escolar na época da ditadura, no desejo de apagar uma consciência crítica, de simplificar as informações, e de não se preocupar com a formação dos professores.

Em uma pesquisa com adolescentes sobre o entendimento do conceito de "nação", realizada por M aria Rosa Chaves Künzle, em duas escolas, uma particular e outra pública, da cidade de Curitiba (Paraná), realizada no ano de 2002,

os alunos concebem a nação como algo que deveria ser, necessariamente, homogêneo e sem conflitos internos; gran des diferenças sociais entre as classes impedem a formação da nação. Segundo a pesquisadora os alunos têm uma idéi dinâmica da nação como al go que se constrói, é uma construção histórica ea visão tradicional de nação como um ser eterno eintocável pare ce ter mudado entre os alunos. (Künzle, 2003, p. 108)

Embora os al unos concebam que a nação é uma construção histórica, portanto dinâmica, processual, admitem que as diferenças sociais, os conflitos internos dificultam a construção de uma nação, pois concebem-na como um corpo homogêneo e sem conflitos.

A identidade social e a formação de uma consciência histórica são constituídas de uma concepção de tempo em que há relações temporais entre o passado, o presente e o futuro, estão em um processo contínuo de mudanças e cada indivíduo faz parte desse processo de transformação, pois o passado nos constitui, forma o nosso social; nós nos encontramos imersos nesta dimensão temporal. Portanto, somos parcialmente responsáveis pela construção do futuro e todos nós participamos dos 
movimentos históricos (eleições, escolhas, posturas éticas, sentimentos valorativos, papéis profissionais) e participamos conscientemente ou não dos processos de transformação.

O conhecimento histórico construído em sala de aula pode algumas vezes estar centrado na cronologia, na informação de fatos descontextualizados para a vida dos alunos, sem nenhuma vinculação com 0 momento presente, mas o conhecimento histórico, a perpetuação das memórias nacionais, acontece tanto no interior do ambiente escolar como fora dele e com diferentes linguagens: está presente nas exposições, nos museus, nos arquivos, nos meios de comunicação (cinema, jornais, televisão, Internet). Cada uma destas formas de ensinar a história implica uma metodologia própria e recursos a serem utilizados. Em cada um deles o historiador está formando a consciência histórica e o sentimento de identidade.

O conceito de identidade aplicado à educação está fundamentado em uma concepção de vida humana e a única forma de realização é na história. É nesta dimensão que o tempo/espaço são categorias explicativas do conhecimento, isto é, têm um passado individual, local sustentado por um social histórico mais amplo do qual fazemos parte.

Recebido em agosto de 2003 e aprovado em setembro de 2003.

\section{Referências bibliográficas}

BALAKRISH NAN, G. (O rg.). U m mapa da questão nacional. Rio de Janeiro: Contraponto, 2000.

CAPELATTO, M.H. Multidões em cena. Campinas: Papirus, 1999.

CHARTIER, R. A história cultural: entre práticas e representações. Rio de Janeiro: Bertrand do Brasil, 1990.

CERRI, L.F. Uma escola do Brasil: o trabalho educativo das imagens da nação no "milagre brasileiro" (1969-1973) e na comemoração dos 500 anos do descobrimento (1998-2000). In: SchmidT, M.A.; Cainelli, M.R. (O rg.). III Encontro Perspectivas do Ensino de H istória. Curitiba: Aos Q uatro Ventos, 1999. p. 453-470. 
DIAS, M .F.S. Invenção da América na cultura escolar. 1997. 176f. Tese (D outorado) - Faculdade de Educação, Universidade Estadual de Campinas, Campinas.

HERRERA, M.C.; DIAZ, C.J. (O rg.). Educação y cultura política: uma mirada multidisciplinaria. Bogotá: Plaza \& Janés, 2001

KÜ N ZLE, M .R.C. 0 ensino de história e o conceito de nação: um instrumento de pesquisa. 2003. Dissertação (M estrado) - Faculdade de Educação, Universidade Federal do Paraná, Curitiba.

M ATO S, O . Construção e desaparecimento do herói: uma questão de identidade nacional. Tempo Social, São Paulo, v. 6, n. 1/2, p. 83-90, jun. 1995.

N AD AI, E. 0 ensino de história no Brasil: trajetórias e perspectivas. Revista Brasileira de H istória, São Paulo, v. 13, n. 25/26, p.143-162, set. 1992/ago. 1993.

RYAN, M . A parada norteamericana: representações sociais do sécuIo XIX. In: H UnT, L. A nova história cultural. São Paulo: M artins Fontes, 2001.

RÜ SEN, J. Razão histórica. Brasília, DF: un B, 2001.

SILLER, J.P.G.; RADKAU, V. (O rg.). I dentidad en imaginário nacional: reescritura y enseñanza de la historia. Puebla, M X.: BUAP, 1998.

SIM AN, L.M .C.; FON SECA, T.N.L. Inaugurando a história e construindo a nação. Belo H orizonte: Autêntica, 2001.

ZAM BON I, E. O rientações metodológicas no currículo e na docência do ensino de história no Brasil. Ágora, Santa Cruz do Sul, v. 4, n. 1/2, p. 07-22, jan./dez. 1998.

ZAM BONI, E. I dentidade nacional e consciência histórica. In: EN CUENTRO INTERNACIONAL DE IN VESTIGADORES DE LA RED - Educación, Cultura y Política em América Latina, 3., 2002, Tandil. Anales.. Tandil, 2002. 